\title{
NARKOBA DI KALANGAN PELAJAR KOTA 'SANTRI' TASIKMALAYA
}

\author{
Ai Kusmiati Asyiah ${ }^{1 *}$, Ristina Siti Sundari ${ }^{1}$, Ade Maftuh ${ }^{1}$, Samsu Herdiana ${ }^{1}$ \\ ${ }^{1}$ Universitas Perjuangan Tasikmalaya, Indonesia \\ *email: aikusmiati71@Gmail.com
}

\begin{abstract}
Abstrak
Penyalahgunaan narkoba pada masyarakat Tasikmalaya semakin mencemaskan. Sebagai salah satu akses dari mudahnya informasi melalui segala media, masyarakat yang kurang filter dalam menyikapi banyak yang terjerumus. Penelitian ini bertujuan untuk mengetahui informasi tentang penyalahgunaan narkoba di kalangan pelajar Tasikmalaya. Metode yang digunakan adalah studi kasus dengan analisis statistika menggunakan analisis linier berganda untuk dapat diketahui ada atau tidaknya pengaruh dari variable internal dan eksternal terhadap 22 orang responden. Hasil penelitian menunjukkan bahwa factor internal yaitu individu dan proses psikologis memiliki pengaruh yang nyata terhadap penyalah gunaan narkoba di kalangan mahasiswa dan pelajar di Tasikmalaya. Begitu juga factor eksternal yaitu lingkungan dan kondisi ekonomi sama berpengaruh nyata dalam kategori tinggi yang menyebabkan terjadinya penyalahgunaan narkoba di kalangan pelajar mahasiswa. Sosialisasi untuk menurunkan factorfaktor internal dan eksternal oleh orang tua, guru, lembaga, media social. Disarankan untuk membuat suatu perkumpulan atau organisasi di lembaga sekolah atau kampus dalam menggalakkan pelajar menjadi kader anti narkoba.
\end{abstract}

Kata kunci: Penyalahgunaan; Narkoba; Pelajar

\begin{abstract}
Drug abuse was getting worried in Tasikmalaya due to easy access to information throughout any medium, especially from the internet in smartphones, almost every teenager's own. Unfortunately, they lack to filter whether the information was positive things or not in response caused drag them in. This research intended to find out information about drug abuse among Tasikmalaya students as a case study. The research was analyzed by simple linear regression regarding internal and external factors toward 22 respondents. The internal factors consisted of individual and psychological components; the external factor consisted of environmental and economic condition components that strongly affected drug abuse. The respondents might be ex-users, users, or in rehabilitation from drugs. The observation result showed that internal factors consisted of the individual and psychological components that significantly affected students' drug abuse. External factors, especially the environment surrounding and economic conditions, affected students' drug abuse in Tasikmalaya, known as an Islamic boarding city. Those are in the high category. These matters need a way out, such as socialization about how harmful the drug abuse and effort to decrease either internal or external factors by the parent, teacher, institution, and social media. It is an excellent idea to establish the organization or community to create the student candidate for antidrugs.
\end{abstract}

Keywords: Abuse; Drug; Student

This is an open access article under the CC BY-SA license.

Copyright (C 2021 by Author. Published by Universitas Pendidikan Ganesha.

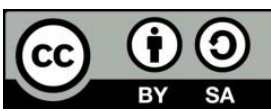

\section{PENDAHULUAN}

$\begin{array}{lrr} & \text { Narkoba } & \text { adalah } \\ \text { merupakan } & \text { kepanjangan } & \text { dari }\end{array}$
Narkotika, dan obat/bahan Bahan berbahaya atau dikenal dengan Narkotika, Psikotropika, dan Zat Adiktif 
lainnya (NAPZA) (Kemenkes, 2014), dimana istilah narkoba sudah sangat sering kita dengar di lingkungan masyarakat pada umumnya. Maraknya peredaran narkoba dewasa ini sudah sangat meresahkan masyarakat tidak hanya usia remaja dikalangan pelajar ataupun mahasiswa, anak-anak bahkan orang dewasa yang dianggap orang tua, lingkungan kerja, masyarakat di desa maupun di kota bisa terlibat dalam lingkaran peredaran dan penyalahgunaan narkoba tersebut (Hasibuan, 2017).

Peredaran narkoba yang saat ini begitu mudah untuk didapatkan menyebabkan orang bisa dengan mudah mengkonsumsi narkoba tersebut dan hal ini menjadi suatu kekhawatiran dimana penyalahgunaan narkoba khususnya di kalangan remaja pelajar semakin bertambah banyak. Sampai saat ini peredaran penyalahgunaan narkoba sudah menyebar sehingga sulit untuk di cegah, mengingat hampir semua penduduk dunia bisa dengan gampangnya mendapatkan narkoba dari orang-orang yang tidak bertanggung jawab dan hal ini membuat orang tua, organisasi dan masyarakat serta Pemerintah merasa khawatir (Amanda et al., 2017).

Begitu pula dengan pengedar dan pengguna narkoba yang kerap beroperasi diwilayah Kota Tasikmalaya sudah semakin meresahkan masyarakat dengan seringnya tertangkap oleh Aparat Kepolisian Kota Tasikmalaya atau juga oleh Badan Narkotika Nasional Kota Tasikmalaya, dimana remaja dan anak-anak tak luput dari sasaran mereka, dan saat ini penyebaran narkoba sudah tidak bisa dicegah lagi karena hampir seluruh penduduk dunia dapat dengan mudah mendapatkan narkoba dari oknum yang tidak bertanggung jawab (Pananjung \& Akbar, 2014).

Banyak faktor yang dapat
mempengaruhi seseorang dapat
menyalahgunakan narkoba dan
mengkonsumsi narkoba yang sudah
menjadi ketergantungan bisa
merugikan dan membahayakan karena

merusak kesehatan dan dapat memiliki potensi merubah fungsi tubuh secara keseluruhan (Refeiater, 2011) bagi seorang pengguna narkoba, sebaliknya apabila narkoba dipergunakan sesuai peruntukannya adalah merupakan obat atau bahan yang dapat berguna dan dibutuhkan dibidang pengobatan atau pelayanan kesehatan.

Sehingga perlu diketahui sejauhmana tingkat konsumsi pelajar terhadap penyalahgunaan narkoba dan bagaimana solusi dalam menanggulangi penyalahgunaan narkoba pada pelajar.

\section{METODE}

Penelitian ini menggunakan metode survey kepada 100 (seratus) orang pelaku penyalahgunaan narkoba yang berada di wilayah Tasikamalaya. Tahapan penelitian dimulai dengan mengidentifikasi jumlah pelaku remaja penyalahgunaan narkoba yang ada di wilayah Tasikmalaya, penyusunan kuisioner, wawancara terhadap pejabat_pejabat yang berwenang dalam menangani kasus narkoba yaitu Badan Narkotika Nasional dan Kepolisian, dengan melaksanakan penelitian, data yang dikumpulkan dan sampel penelitian, uji dan analisis sampel.

\section{Jenis Sumber Data}

Pengumpulan data dalam penelitian ini adalah data primer yang diperoleh dari hasil kuisioner terhadap pelaku penyalahgunaan narkoba dan hasil wawancara terhadap pejabatpejabat yang berwenang dalam menangani kasus narkoba yaitu Badan Narkotika Nasional dan Kepolisian. Data sekunder, yaitu data yang di dapat dari hasil studi pustaka, jurnal penelitian, bahan publikasi dan Dinas terkait yang ada hubungannya dengan penelitian ini.

\section{Teknik Penentuan Responden}

Teknik penentuan responden dilakukan dengan sengaja (purposive judgement sampling) di ambil dari para pelaku penyalahgunaan narkoba yang sudah selesai menjalani pidananya dan 
terhadap para pelaku penyalahgunaan narkoba yang masih dalam tingkat pemeriksaan baik di kepolisian, kejaksaan maupun pengadilan.

\section{Operasionalisasi Variabel}

Variabel yang digunakan dalam penelitian tentang narkoba di kalangan pelajar di Tasikmalaya yaitu ingin mengetahui faktor yang dianggap penting dalam hal-hal yang mempengaruhi remaja pelajar yang melakukan penyalahgunaan narkoba dan mencari untuk kemudian didapatkan solusi untuk mengatasi penyalahgunaan narkoba dan variabelvariabel tersebut adalah sebagai berikut:

1. Pelaku adalah setiap orang yang melakukan penyalahgunaan narkoba, diantaranya:

a. Pengguna yaitu seseorang yang memiliki narkoba dan untuk dikonsumsi sendiri;

b. Pengedar yaitu seseorang yang memiliki narkoba untuk orang lain;

2. Perilaku adalah sikap, tindak dan ucap dari pelaku penyalahgunaan narkoba:

3. Narkoba yaitu zat yang disalahgunakan oleh pelaku yang terdiri dari:

a. Narkotika yaitu salah satu golongan narkoba yang mana dibuat dari suatu tanaman atau non tanaman yang baik sentetis maupun semi sintetis dan bisa menyebabkan perubahan dan penurunan kesadaran;

b. Psikotropika adalah merupakan bahan yang sifatnya alami ataupun tidak alami yang memiliki sifat psikoaktif yang bisa mempengaruhi susunan syaraf yang dapat berdampak pada perubahan mental dan perilaku;

c. Zat adiktif adalah tidak termasuk narkotika ataupun psikotropika, zat ini merupakan bentuk inhalasi dan zat adiktif ini pada kadar tertentu dapat memberikan efek kecanduan;
4. Pengaruh yaitu hal-hal yang dapat mendorong seseorang untuk melakukan penyalah gunaan narkoba yaitu:

a. Pengaruh Internal yaitu pengaruh yang ada dari dalam diri pribadi seseorang pelaku narkoba itu sendiri

b. Pengaruh eksternal yaitu pengaruh yang ada diluar dari pribadi seseorang pelaku narkoba.

Kombinasi variabel dilakukan untuk mendapatkan penilaian responden terhadap variable yang diamati. Setelah dilakukan operasional variable kemudian dilakukan pengumpulan data dengan tahapan penentuan sampel penelitian. Penilaian dilakukan dengan skala likers seperti pada tabel dibawah ini.

Tabel 1. Skala Likert Kuesioner

\begin{tabular}{ccc}
\hline No. & Pernyataan & Skor \\
\hline 1. & Sangat suka/setuju & 5 \\
2. & Suka/setuju & 4 \\
3. & Cukup Suka/setuju & 3 \\
4. & Tidak Suka/setuju & 2 \\
5. & Sangat Tidak Suka/setuju & 1 \\
\hline
\end{tabular}

\section{Rancangan Analisis Data}

Setelah angket dikumpulkan dari responden yang menyangkut narkoba dikalangan pelajar di Tasikmalaya, langkah selanjutnya ditabulasi dan dianalisis, kuisioner yang dibuat menggunakan Skala Likers dengan pembobotan melalui skor 5-43-2-1.

Rumus yang digunakan untuk melakukan analisis data, yakni Nilai Tertimbang (Djoni, 2008) sebagai berikut.

$$
\mathrm{NT}=\frac{\text { nilai yang dicapai }}{\text { nilai ideal }(\text { maksimum })} \times 100 \%
$$

Sistem skoring dan kisaran skor masing-masing indicator serta klasifikasi indicator dari variabel pertama dijabarkan dalam Tabel 2 dan Tabel 3

Nilai dan kisaran Skoring pada indicator dan variable pelaku penyalahguna narkoba 
Tabel 2. Nilai dan Kisaran Skoring pada Indikator dari Variabel Penelitian

\begin{tabular}{lcc} 
No. & Indikator & Kisaran Skor \\
\hline 1. & Faktor nternal & $10-50$ \\
2. & Faktor Eksternal & $10-50$ \\
\hline Jumlah Skoring & $20-100$ \\
\hline
\end{tabular}

Penentuan interval kelas untuk indicator dan variable pelaku penyalahguna narkoba formulasi nya sebagai berikut.
Klasifikasi $=\frac{\text { Skor Maksimal-Skor Minimal }}{\text { Jumlah Kategori }}$

Berdasarkan hasil perhitungan maka diperoleh hasil klasifikasi dan sistem skoring serta kisaran skor masingmasing indikator serta klasifikasi indikator dari variable kedua dijabarkan dalam Tabel 3 dan 4 berikut.

Klasifikasi Indikator dari Variabel pelaku penyalahgunaan narkoba

Tabel 3. Klasifikasi Indikator dari Variabel Penelitian

\begin{tabular}{ccccc}
\hline \multirow{2}{*}{ No. } & Indikator & \multicolumn{3}{c}{ Klasifikasi (Nilai/Skor) } \\
\cline { 3 - 5 } & & Rendah & Sedang & Tinggi \\
\hline 1. & Faktor Internal & $10,00-29,90$ & $30,00-39.00$ & $40,00-50,00$ \\
2. & Faktor Eksternal & $10,00-29,90$ & $30,00-39.00$ & $4000-50,00$ \\
\hline \multicolumn{2}{r}{ Penyalahguna Narkoba } & $20,00-59,00$ & $60,00-84,00$ & $80,00-100,00$ \\
\hline
\end{tabular}

Tabel 4. Nilai dan Kisaran Skoring pada Indikator dari Variabel Penelitian

\begin{tabular}{llc}
\hline No. & Indikator & Kisaran Skor \\
\hline 1. & Individu & $6-30$ \\
2. & Lingkungan & $18-90$ \\
3. & Proses & $9-45$ \\
& Psikologis & $3-15$ \\
4. & Ekonomi & $36-180$ \\
\hline
\end{tabular}

Penentuan interval kelas untuk indikator dari variabel menggunakan narkoba formulasi nya sebagai berikut.
Klasifikasi $=\frac{\text { Skor Maksimal-Skor Minimal }}{\text { Jumlah } \text { Kategori }}(4)$

Berdasarkan hasil perhitungan maka diperoleh hasil berikut.

Tabel 5. Klasifikasi Indikator dan Variabel pengaruh menyalahgunakan narkoba

\begin{tabular}{llccc}
\hline \multirow{2}{*}{ No. } & \multicolumn{3}{c}{ Indikator } & \multicolumn{3}{c}{ Klasifikasi (Nilai/Skor) } \\
\cline { 2 - 5 } & Individu & $6,00-13,00$ & Sedang & Tinggi \\
\hline 1. & Lingkungan & $18,00-40,00-21,00$ & $22,00-30,00$ \\
3. & Proses Psikologis & $9,00-20,00$ & $41,00-70,00$ & $71,00-90,00$ \\
4. & Ekonomi & $3,00-6,00$ & $7,00-30,00$ & $31,00-45,00$ \\
\hline \multicolumn{2}{l}{ Penyalahgunaan narkoba } & $36,0-79,0$ & $83,00-131,00$ & $11,00-15,00$ \\
\hline
\end{tabular}

Sumber: Data primer diolah

Uji koefisien determinasi bertujuan untuk mengetahui seberapa jauh kemampuan sebuah model dalam menerangkan variansi variabel dependen (Nazir, 2013). Analisis yang memiliki varabel bebas lebih dari satu disebut analisis regresi liner berganda. Regresi linear berganda ini digunakan guna mengetahui ada atau tidaknya pengaruh signifikasi minimal dua variabel bebas $\left(X_{1}\right.$ dan $\left.X_{2}\right)$ terhadap variabel terikat yaitu penyalahgunaan narkoba di kalangan remaja (Y). Model regresi linear berganda dalam penelitian ini adalah sebagai berikut.

$$
Y=\beta_{0}+\beta_{1} X_{1}+\beta_{2} X_{2}+e
$$

Keterangan :

$Y \quad:$ Penyalahgunaan Narkoba

$\beta_{O} \quad$ : Konstanta

$\beta_{1}, \beta_{2}$ : Koefisien regresi 
$X_{1} \quad:$ Faktor internal

$X_{2} \quad$ : Faktor eksternal

$e \quad$ : Variabel diluar model yang dapat mempengaruhi variabel dependen.

Uji F dilakukan untuk mengetahui secara serentak atau bersama-sama variabel independen berpengaruh secara sigfikan atau tidak terhadap variabel dependen. $H_{0}: \beta=0$ artinya, tidak ada pengaruh antara variabel bebas simultan terhadap penyalahgunaan narkoba di kalangan mahasiswa dan pelajar.

Ha: $\beta>0$ artinya, ada pengaruh antara variabel bebas secara simultan terhadap penyalahgunaan narkoba di kalangan mahasiswa dan pelajar.

$F=\frac{(n)-(K-1) R^{2}}{(1-R)(K)}$

Keterangan:

$\mathrm{R}=$ Koefisien korelasi berganda

$\mathrm{K}=$ Jumlah variabel bebas

$\mathrm{n}=$ Jumlah sampel

Dengan tingkat signifikasi ( $\alpha$ ) yang digunakan adalah $5 \%$, distribusi $F$ dengan derajat kebebasan ( $\alpha$ : K-1, n-K).

Bila $\mathrm{F}$ hitung $<\mathrm{F}$ Tabel maka $\mathrm{H}_{0}$ diterima, artinya variabel secara signifikan. Bila $F$ hitung $>F$ Tabel maka $\mathrm{H}_{0}$ ditolak, artinya variabel secara serentak atau bersama-sama mempengaruhi variabel secara signifikan. Uji t secara individual (uji-t) yaitu pengujian koefisien regresi secara parsial dengan menentukan formula statistik yang akan diuji, untuk mengetahui apakah suatu variabel secara parsial berpengaruh nyata atau tidak, Untuk melakukan uji $t$ ada beberapa langkah yang diperlukan yaitu: Variabel bebas berpengaruh tidak nyata apabila nilai koefisienya sama dengan nol, sedangkan variabel bebas akan berpengaruh nyata apabila nilai koefisienya tidak sama dengan nol. Hipotesis selengkapnya adalah: $\mathrm{H}_{0}=\mathrm{b}_{1}$ : $\mathrm{b}_{2}:=0, \mathrm{Ha}=\mathrm{b}_{1}: \mathrm{b}_{2}: \neq 0$

$$
\mathrm{t} \text { hitung }=\frac{b i}{S e i}
$$

dimana: $S_{\text {ei }}=$ standar error. bi $=$ koefisien regresi. Tingkat signifikan pada peneltian ini adalah sebesar 0.05 (5\%) dengan tingkat kepercayaan 0,95 (95\%). Nilai tTabel dapat dilihat dengan tarif sifnifikan dan derajat kebebasan

$(d f)=n-k-2$

$\mathrm{H}_{0}$ ditolak dan $\mathrm{H}_{\mathrm{a}}$ diterima jika $t_{\text {hitung }}>\mathrm{t}_{\text {Tabel }}$ $\mathrm{H}_{0}$ diterima dan $\mathrm{H}_{\mathrm{a}}$ ditolak jika thitung $>\mathrm{t}_{\text {Tabel }}$ Jika $\mathrm{H}_{0}$ diterima dan $\mathrm{H}_{a}$ ditolak dapat disimpulkan bahwa faktor internal dan eksternal. Jika $\mathrm{H}_{0}$ ditolak dan $\mathrm{H}_{\mathrm{a}}$ diterima dapat disimpulkan bahwa faktor internal dan eksternal berpengaruh terhadap penyalahgunaan narkoba di kalangan mahasiswa dan pelajar

\section{HASIL DAN PEMBAHASAN}

Wilayah Penelitian meliputi Kota Tasikmalaya dimana letak secara geografis berada pada $108^{\circ} 24^{\prime} 02$ " BT dan $7^{0} 10^{\prime}$ LS - $7^{0}$ 26'32"LS. Posisi ini merupakan posisi strategis di bagian tenggara Provinsi Jawa Barat. Luas wilayah Kota Tasikmalaya berdasarkan Perda Kota Tasikmalaya Nomor 4 Tahun 2012 Tentang Rencana Tata Ruang Wilayah Kota Tasikmalaya tahun 2011 adalah 183,85 km².

Batas-batas wilayah Kota Tasikmalaya yaitu sebelah utara berbabatasan dengan Kab. Tasikmalaya dan Kab. Ciamis (dengan batas sungai citanduy), sebelah barat dengan kab. Tasikmalaya, sebelah timur dengan Kab. Tasikmalaya dan Kab. Ciamis dan sebelah selatan dengan kab. Tasikmalaya (batas Sungai Ciwulan). Pada tahun 2018 penduduk Kota Tasikmalaya mencapai 662.723 jiwa, komposisi penduduk usia 15 - 64 tahun mencapai 67,43 persen, penduduk $0-14$ tahun sebesar 27,47 persen, dan penduduk usia 65 tahun ke atas sebesar 5,10 persen (BPS, 2020)

Angka Partisipasi Sekolah (APS) menggambarkan penduduk usia sekolah yang sedang sekolah. Dari data APS ini bisa dilihat perjenjang usia yaitu Usai SD (7-12 tahun), SMP (13-15 tahun) dan SMA (16-18 tahun). Di Kota Tasikmalaya APS paling tinggi yaitu pada usia SD sebesar 99,52 persen, yang artinya 
hamper semua penduduk usia sekolah SD di Kota Tasikmalaya sedang mengenyam pendidikan SD, yang paling rendah adalah usia SMA yaitu sebesar 67,17 persen (BPS, 2020)

Tasikmalaya terkenal dengan sebutan kota santri secara logika masyarakatnya bisa dikatakan banyak yang menjadi santri dan banyak orang yang datang ke Tasikmalaya untuk menjadi santri di Tasikmalaya, sehingga dengan sendirinya banyak terdapat juga pesantren-pesantren untuk menampung santri-santri yang menimba ilmu di pesantren, dengan kondisi masyarakat
Tasikmalaya yang seperti ini menjadi godaan atau tantangan tersendiri untuk dapat dijadikan tempat peredaran narkoba dengan sasaran usia produktif.

Diharapkan dengan target luaran ini yaitu untuk menjadikan masyarakat Kota Tasikmalaya, khususnya kalangan remaja yaitu pelajar dan mahasiswa yang ada di Kota Tasikmalaya terbebas dari pengaruh narkoba dan bersih dari narkoba sehingga menjadikan ramaja Kota Tasikmalaya menjadi remaja sebagai generasi penerus bangsa yang berkualitas.

Tabel 6 analisis nilai penyebab penyalahgunaan narkoba

\begin{tabular}{cccccc}
\hline No. & Indikator & $\begin{array}{c}\text { Nilai } \\
\text { Ideal }\end{array}$ & $\begin{array}{c}\text { Nilai yang } \\
\text { diperoleh }\end{array}$ & $\begin{array}{c}\text { NT } \\
(\%)\end{array}$ & Kategori \\
\hline 1 & Individu & 30 & 16,23 & 54,09 & Sedang \\
2 & Lingkungan & 90 & 56,455 & 62,73 & Tinggi \\
3 & Proses Psikologis & 45 & 29,86 & 66,36 & Tinggi \\
4 & Ekonomi & 15 & 9,23 & 61,51 & Tinggi \\
\hline
\end{tabular}

Tabel 6 memperlihatkan bahwa indikator individu memiliki katagori yang sedang dalam terjadinya penyalahgunaan narkoba di kalangan pelajar dan mahasiswa. Sedangkan faktor lingkungan memperlihatkan kategori yang tinggi dengan nilai tertimbang 62,73\%. Demikian juga dengan proses psikologis dan factor ekonomi sangat berhubungan terhadap terjadinya penyalahgunaan narkoba di kalangan pelajar dan mahasiswa, dengan nilai tertimbang secara berturut turut $66,52 \%$ dan $61,51 \%$.

Dari data yang didapat untuk penyalahguna narkoba di Tasikmalaya rata-rata usia produktif antara usia 17 50 tahun, dan ada beberapa usia di bawah 17 tahun dengan kategori anakanak. Untuk kalangan remaja usia 17-30 tahun yaitu pelajar dan mahasiswa, narkoba yang sering dikonsumsi oleh kalangan usia remaja ini yaitu jenis psykotropika, ganja dan bahan berbahaya lain nya yaitu jenis obat keras tertentu seperti obat batuk, obat syaraf (Parkinson) yang diracik sendiri atau dioplos, minuman keras/beralkohol, sedangkan usia di atas 30 rata-rata mengkonsumsi narkotika jenis ganja, ekstasi dan sabu. (data BNN \& SAT. Narkoba POLRES Kota Tasikmalaya)

\section{Hasil Uji Koefisien Determinasi}

Tabel 7 Uji Koefisien Determinasi

\begin{tabular}{lrrrr}
\hline Model & $\mathrm{R}$ & $\begin{array}{c}\mathrm{R} \\
\text { Square }\end{array}$ & $\begin{array}{c}\text { Adjusted } \\
\mathrm{R} \\
\text { Square }\end{array}$ & $\begin{array}{r}\text { Std. Error of } \\
\text { the Estimate }\end{array}$ \\
\hline 1 & $.789^{\mathrm{a}}$ & .623 & .583 & .25486 \\
\hline
\end{tabular}

a. Prediktor: (konstanta), X2, X1

Berdasarkan tabel 7 memperlihatkan nilai determinasi $R^{2}$ adalah 0.623 yang berarti variable factor internal dan external sebagai variable bebas terhadap penyalahgunaan narkoba sebagai variable terikat memberikan kontribusi sebesar 62,3 persen sedangkan sisanya sebesar 37,7 persen dipengaruhi oleh variable lain yang tidak termasuk dalam penelitian ini.

Variabel independen yaitu factor internal (X1) dan eksternal (X2) secara simultan berpengaruh sangat nyata 
Ai Kusmiati Asyiah, Ristina Siti Sundari, Ade Maftuh, Samsu Herdiana | Narkoba Di Kalangan Pelajar Kota 'Santri' Tasikmalaya

dengan nilai signifikansi 0.000 terhadap penyalahgunaan narkoba di kalangan mahasiswa dan pelajar. Secara lengkap dapat dilihat pada table 8 .

Tabel 8 Analisis Sidik Ragam (Uji F)

\begin{tabular}{|c|c|c|c|c|c|c|}
\hline & Model & $\begin{array}{l}\text { Jumlah } \\
\text { Kuadrat }\end{array}$ & Derajat bebas & Kuadrat Tengah & $\mathrm{F}$ & Sig. \\
\hline \multirow{3}{*}{1} & Regresi & 2.039 & 2 & 1.019 & 15.692 & $0.000^{b}$ \\
\hline & Galat & 1.234 & 19 & .065 & & \\
\hline & Total & 3.273 & 21 & & & \\
\hline
\end{tabular}

b. Prediktor: (Constant), X2, X1

Tabel 9. Hasil Uji t

\begin{tabular}{|c|c|c|c|c|c|c|}
\hline \multirow{2}{*}{\multicolumn{2}{|c|}{ Model }} & \multicolumn{2}{|c|}{ Koefisien tadk terstandar } & \multirow{2}{*}{$\begin{array}{c}\text { Koefisien terstandar } \\
\text { Beta }\end{array}$} & \multirow[t]{2}{*}{$\bar{T}$} & \multirow[t]{2}{*}{ Sig. } \\
\hline & & $\mathrm{B}$ & Std. Error & & & \\
\hline \multirow{3}{*}{1} & (C) & 1.274 & .676 & & 1.886 & .075 \\
\hline & Faktor internal X1 & .038 & .012 & .647 & 3.172 & .005 \\
\hline & Faktor eksternal X2 & .101 & .018 & 1.118 & 5.484 & .000 \\
\hline
\end{tabular}

a. Variabel terikat: $Y$

Berdasarkan Tabel 9 dapat diketahui bahwa variable X1 yaitu faktor internal memberikan nilai t hitung yang lebih besar dari nilai indicator signifikansi. Hal ini menunjukkan bahwa factor internal yaitu individu dan proses psikologis berpengaruh nyata terhadap penyalahgunaan narkoba di kalangan mahasiswa dan pelajar di kota Tasikmalaya. Hal ini dapat dimaknai bahwa semakin tinggi factor internal dari mahasiswa dan pelajar maka semakin tinggi juga untuk terlibat dalam penyalahgunaan narkoba.

Demikian juga faktor eksternal yaitu lingkungan dan ekonomi memberikan pengaruh yang sangat nyata dengan nilai t 5,484 terhadap sig. 0.000 terhadap penyalahgunaan narkoba di kalangan mahasiswa dan pelajar Kota Tasikmalaya. Hal ini dimaknai bahwa semakin kuat factor eksternal maka semakin mudah mahsiswa dan pelajar Kota Tasikmalaya terlibat dalam penyalahgunaan narkoba. Bahkan nilai uji menunjukkan bahwa factor eksternal yaitu lingkungan dan ekonomi lebih besar pengaruhnya dari pada factor internal yaitu individu dan proses psikologis. Oleh karena itu, para orang tua, guru dan masyarakat harus lebih berwaspada dan secara psikologis anak remaja dapat dengan mudah terpengaruh bermula dari lingkungan (Melati, 2017).

Berdasarkan output tersebut penyalahgunaan narkoba di kalangan pelajar dan mahasiswa secara signifikan dipengaruhi oleh factor eksternal dan jika faktor internal yang lemah dimiliki oleh seseorang akan dengan sangat mudah untuk seseorang tersebut dapat melakukan penyalahgunaan narkoba apabila ditambah oleh pengaruh ekternal yaitu lingkungan dimana pengaruh lingkungan sangat kuat sekali pengaruhnya dibanding dengan faktorfaktor yang lainnya.

Faktor lingkungan yaitu lingkungan tempat tinggal, lingkungan bermain, dan lingkungan sekolah atau kampus sudah menjadi tempat pengedaran dan penyalahgunaan narkoba dan di Tasikmalaya. Berdasarkan wawancara dengan responden Badan Narkotika Nasional dan satuan Narkoba Polres Kota Tasikmalaya untuk penyalahgunaan narkoba ada terjadi dilingkungan kampus maupun sekolah yang ada di Tasikmalaya, demikian pula sama halnya faktor lingkungan yang sangat berpengaruh apalagi pergaulan antar teman dengan gaya nya pergaulan dan solidaritas antar teman sesorang amampu melakukan penyalahgunaan narkoba (Amanda et al., 2017). 
Pengungkapan kasus yang dilakukan oleh Satuan Narkoba Polres Tasikmalaya Kota untuk tahun 2018 sebanyak 48 kasus dan untuk tahun 2019 sebanyak 52 kasus dengan demikian ada peningkatan kasus dari tahun sebelumnya, dan dari jumlah kasus selama 2 (dua)tahun tersebut rata -rata penyalahguna narkoba didominan oleh usia 17 - 35 tahun.

Pengungkapan kasus yang dilakukan oleh Badan Narkotika Nasional Tasikmalaya untuk tahun 2018 sebanyak 14 kasus dan untuk tahun 2019 sebanyak 20 kasus hal inipun sama demikian meningkat dari tahun sebelumnya, dan dari jumlah kasus selama 2 (dua) tahun tersebut rata-rata didominasi oleh usia yaitu usia produktif yaitu 14- 50 tahun.

Para penyalahguna narkoba selain dilakukan proses hukum oleh penyidik Satuan narkoba Polres Tasikmalaya Kota selebihnya dilakukan rehabilitasi oleh Badan narkotika nasional Kota Tasikmalaya akan tetapi kemampuan rehabilitasi medis yang terbatas hanya rawat jalan dan belum mempunyai rawat inap medis yang ada di Kota Tasikmalaya apabila dibandingkan dengan wilayah lain seperti Palembang telah mempunyai panti rehabilitasi (Hawi, 2018).

Rehabilitasi medis yang dilakukan di Badan Narkotika Nasional Tasikmalaya yaitu rehabilitasi rawat jalan dimana seseorang yang direhabilitasi dilakukan pengobatan medis yaitu terapi obat dengan pengawasan dokter, kemudian konseling tujuannya membantu program pemulihan seperti memulai kembali hidup sehat dan strategi menghadapi kondisi dimana penyalahgunaan narkoba terulang kembali, hal ini sebagaimana menurut Pasal 127 UU Narkotika ayat 3 yaitu penyalahgunaan narkoba yang dapat dibuktikan jikalau penyalah guna tersebut terbukti sebagai korban maka wajib menjalani rehabilitasi (MPR, 2009).

\section{SIMPULAN DAN SARAN}

pelajar Kota Tasikmalaya dalam

penyalahgunaan narkoba secara simultan dipengaruhi oleh dua factor utama yaitu factor internal diantaranya individu dan proses psikologis dan eksternal yaitu lingkungan dan ekonomi. Secara parsial, factor internal mempengaruhi keterlibatan mahasiswa dan pelajar dalam penyalahgunaan narkoba. Semakin tinggi factor internal maka akan semakin kuat mahasiswa dan pelajar untuk terlibat penyalahgunaan narkoba. Faktor eksternal sangat kuat mempengaruhi keterlibatan mahasiswa dan pelajar Kota Tasikmalaya terhadap penyalahgunaan narkoba.

Ada hubungan yang kuat dan searah Antara faktor internal yaitu individu dan psikologis dengan faktor eksternal yaitu Lingkungan dan ekonomi untuk melakukan penyalahgunaan narkoba di kalangan pelajar dan mahasiswa. Faktor internal yang lemah dimiliki oleh seseorang dapat dipengaruhi kuat oleh faktor eksternal untuk mendorong seseorang melakukan penyalahgunaan narkoba, meskipun tidak sedikit pula seseorang melakukan penyalahgunaan narkoba hanya karena satu faktor pengaruh saja.

\section{DAFTAR PUSTAKA}

Amanda, M. P., Humaidi, S., \& Santoso, M. B. (2017). Penyalahgunaan Narkoba Di Kalangan Remaja (Adolescent Substance Abuse). Prosiding Penelitian Dan Pengabdian Kepada Masyarakat, 4(2), 339-345. https://doi.org/10.24198/jppm.v4i2.1 4392

BPS. (2020). Kota Tasikmalaya 2020. In BPS Kota Tasikmalaya/BPSStatistics of Tasikmalaya Municipality.

https://tasikmalayakota.bps.go.id/pu blication/2020/02/28/c5a5ac8299cf2 $672 \mathrm{cc} 421 \mathrm{fda} /$ kota-tasikmalayadalam-angka-2020--penyediaandata-untuk-perencanaanpembangunan.html

Hasibuan, A. A. (2017). Narkoba dan Penanggulangannya. Jurnal IImiah Bidang Pendidikan, 11(1), 33-44. http://jurnal.uinbanten.ac.id/index.ph 
$\mathrm{p} /$ studiadidaktika/article/view/517/44

5

Hawi, A. (2018). Remaja Pecandu Narkoba: Studi Tentang Rehabilitasi Integratif Di Panti Rehabilitasi Narkoba Pondok Pesantren ArRahman Palembang. Tadrib: Jurnal Pendidikan Agama Islam, 4(1), 99119.

https://doi.org/10.19109/tadrib.v4i1 . 1958

Kemenkes. (2014). Gambaran Umum penyalahgunaan narkoba di Indonesia. Buletin Jendela Data Dan Informasi Kesehatan, 5-19.

Melati, D. P. (2017). Pengaruh Penyalahgunaan Narkotika Terhadap Perilaku Kriminal Bagi Remaja. Darmajaya, 1, 60-74. https://jurnal.darmajaya.ac.id/index. php/PSND/article/view/859/529

MPR. (2009). Undang-undang RI Nomor 35 Tahun 2009 Tentang Narkotika.

Nazir, M. (2013). Metode Penelitian (R. Sikumbang (ed.)). Ghalia Indonesia.

Pananjung, L. K., \& Akbar, N. N. (2014). Peranan badan Narkotika Nasional (BNN) dalam Hukum Terhadap Pelaku Penyalahgunaan Narkotika Untuk Dirinya Sendiri ( Pecandu ) Di Indonesia. Jurnal Hukum Pidana Dan Penanggulangan, 3(3), 241247.

https://jurnal.uns.ac.id/recidive/articl e/viewFile/40528/26703

Refeiater, U. H. (2011). Penyalahgunaan Narkoba. Jurnal Health \& Sport, 2(1), $\quad$ 83-88. https://ejurnal.ung.ac.id/index.php/J HS/article/view/65/60 